\title{
Proceeding
}

Supplementary Issue: Winter Conferences of Sports Science. Costa Blanca Sports Science Events, 25-26 January 2019.

Alicante, Spain

\section{Proposed exercises and its effects on some kinematic variables and achievement for 800 meters jogging activity for men}

\author{
GAHFAR S. ESSA \\ Faculty of Physical Education and Sports Science, Wasit University, Iraq
}

\begin{abstract}
This research aims to prepare a proposed training curriculum and to identify the impact of the proposed training curriculum on some Kinematic variables and achievement for 800-meters jogging activity for men. Research area contained the human field for the players of Maysan province youth category, for 800 -meter jogging activity for the sports year 2018; from 20/6/2018 to 28/8/2018 in Maysan Olympic stadium, and scout camp stadium for athletics in Maysan province. Researcher used an experimental method by using a onegroup method to solve the research problem. Choosing the research community was in an unintentional way, and that was represented by the players of Maysan province, youth category for the sports year 2018. They were eight players and the research samples were six players. Two players were excluded after conducting an exploratory experiment on them, and they formed $75 \%$ of the original community. The proposed exercises contributed very clearly and effectively in developing the speed rate. And it had an obvious effect on developing the step length. The researcher advises the Iraqi trainers to rely on effective modern methods, and incorporate them into their training programs and the need to emphasize on developing the kinematic variables during the 800-meter jogging training. Key words: Kinematic variables; Arena and field; 800 -meter race; Biomechanics.
\end{abstract}

\section{Cite this article as:}

Essa, G.S. (2019). Proposed exercises and its effects on some kinematic variables and achievement for 800 meters jogging activity for men. Journal of Human Sport and Exercise, 14(2proc), S263-S273. doi:https://doi.org/10.14198/ihse.2019.14.Proc2.16

Corresponding author. Faculty of Physical Education and Sports Science, Wasit University, Iraq. https://orcid.org/0000-0002$1012-5558$

E-mail: Dr.GhafarSaeedlssa@gmail.com

Supplementary Issue: Winter Conferences of Sports Science. Costa Blanca Sports Science Events, 25-26 January 2019. Alicante, Spain.

JOURNAL OF HUMAN SPORT \& EXERCISE ISSN 1988-5202

(c) Faculty of Education. University of Alicante.

doi:10.14198/jhse.2019.14.Proc2.16 


\section{INTRODUCTION}

The scientific and technical developments that the world had witnessed nowadays, was as a result of the application of modern scientific and technological foundations, which have contributed to the development of the sporting levels of the different games witnessed a remarkable development especially in the international championships.

And as a result of this development, the world countries have started a programmed and precise planning for the training process،and the competition has begun to heighten among these countries to innovate modern scientific means, conducting studies and researches, attention to the basic factors that are involved in the implementation of modern training methods, and attention to the physical aspects of the game as well as the mechanical factors.

The biomechanics is a modern science that had influenced the scientific progress of human Kinematic performance. The Kinematic analysis also contributes to the detection of new methods for athletic techniques, and is used to solve technical problems related to learning and training, where it diagnoses and compares the movements as it adopts the exact measurement to reveal the technical details of the performance in its external form.

Athletic events are activities that have a physical, psychological and physiological activity, where these events have seen major interest in the research and studies field. Where it is distinguished from other games as a competition between individuals, to demonstrate their efficiency and physical ability to achieve new accomplishment; therefore, the trainers seek to find new modern and training methods to reach the highest levels by preparing the player physically, psychologically, artistically and educationally.

And the 800-meter jogging activity is one of the athletic activities that depend on the efficiency of physical and bio-kinematics variables of the runner, which necessitates the trainers to choose the best training methods that have an influence on developing these variables to keep pace with the achievement level for this event.

Thus, the importance of the research indicates the knowledge for the proposed exercises and their impact on the Kinematic variables and the achievement of the 800-meters jogging activity.

\section{The research problem}

Due to the researcher' experience in the track and field games, and their knowledge in the achieved figures in the 800-meters jogging activity, they noticed a vulnerability and declining in the accomplishment level in this event if it compared with the Arab, Asian, and global levels.

This led the researcher to prepare proposed exercises, and the aim of them was to develop some Kinematic variables, and achievement to overcome the poor accomplishment problem in this event, an attempt from us to convey this activity to the continental and global levels.

Research objectives:

-Preparing a proposed training curriculum. -Identifying the impact of the proposed training curriculum on some kinematic variables, and achievement for 800-meters jogging activity for men for research sample personnel. 
Impose research:

There are statistically significant differences between the post and pre-test results for some kinematic variables, and achievements for men research sample personnel, and in favour of the post-test.

Research fields:

Human field: Maysan province player's men category for 800-meters running activity for the athletic year 2018.

Temporal sphere:

The period from $20 / 6 / 2018$ to $28 / 8 / 2018$.

Spatial sphere:

Maysan Olympic Stadium, and scout camp stadium for athletics in Maysan province.

\section{MATERIALS AND METHODOLOGY}

Researcher used an experimental method by using a one-group method to solve the research problem.

\section{Participants}

The sample selection process has a close connection with the community nature from which the sample was taken, because" it is the part for the original community or the model in which the researcher is doing his work.

Hence, the research community was chosen in an unintentional way, and that was represented by the players for Maysan province, youth category for the sport year 2018. They were eight players and the research samples were six players. Two players were excluded after conducting an exploratory experiment on them, and they formed $75 \%$ of the original community.

\section{Measures}

- Tests and measurements.

-Arab and foreign scientific references and the Internet.

Devices and tools used in the search:

-Athletic game playground.

-Watches (6).

- Tape measuring 30 meters (1).

-Whistles and banners for arbitration (2).

-1-meter-long drawing scale (2).

-2 cameras (Konica) type with speed frequency (300) picture per second with a tripod.

-10 barriers.

-Multi-weight medical balls. 


\section{Procedures}

Researcher prepared the proposed training curriculum to develop some Kinematic experiments. And the proposed trial period was 8 weeks, with 3 units, (Saturday, Monday and Wednesday) each week, and the main time section of the unit was (55-60) minutes. The training curriculum was applied during the special preparation period, with high-intensity style.

Kinematic variables:

- $\quad$ Rising angle for distance from $(150,350,550,750) \mathrm{m}$

- $\quad$ Landing angle for distance from $(150,350,550,750) \mathrm{m}$

- $\quad$ Speed rate for distance from $(150,350,550,750) \mathrm{m}$

- $\quad$ Step length for distance from $(150,350,550,750) \mathrm{m}$

Reconnaissance experience:

Researcher conducted the exploratory experiment on Wednesday 20/6/2018, in order to identify the most important difficulties associated with the field research procedures. And the objective was to determine the amount of time in performing the experiment, the number of cameras used, and to reach the best distance to the camera).

The Pre-tests:

The Pre-tests was conducted on Thursday 21/6/2018 on all research sample personnel, and at the scout camp stadium at 4 p.m. with the presence of all research sample personnel, and through this, all the research variables under study were obtained.

The post-tests:

The main experiment was conducted on Thursday 23/8/2018 at the scout camp stadium.

The researcher took into account the same conditions and time in which the pre-test was conducted, where the 800-meters running test was conducted on all research sample personnel, and the International Federation was applied in all aspects of the selection.

The research sample personnel were filmed, through that the search variables were obtained and the researcher analysed those variables through (Kinovea) software.

Video recording:

The researcher filmed the research sample personnel by using two cameras (Kohica) with a frequency of 300 frames per second with a tripod, and the height of camera lens centre was (1.28) of the ground, at a vertical angle on the jogging field. A camera was placed at (4.50) meters away from the jogging area, and researcher used a meter-long drawing scale.

\section{Analysis}

Researcher used the statistical pouch (SPSS) to extract the following values:

- $\quad$ Arithmetic mean

- $\quad$ standard deviation

- $\quad$ Calculated (T) value for symmetrical sample 


\section{RESULTS}

-We note that when we use the proposed exercises, it had a prominent role in developing the rising angle.

- Using the proposed exercises developed the landing angle during the running.

-The proposed exercises have contributed in a clear and effective way in the development of the speed rate -The proposed exercises had the obvious effect on developing the step length

\section{DISCUSSION}

View, analyse, and discuss the results of the search sample tests for the rising angle variable.

Table 1. Arithmetic mean, standard deviation, and Calculated $(\mathrm{T})$ tabular values for the post and pre-tests for rising angel variable

\begin{tabular}{|c|c|c|c|c|c|c|c|c|}
\hline \multirow[t]{2}{*}{ Variable } & \multirow{2}{*}{$\begin{array}{l}\text { Measure } \\
\text { Unit }\end{array}$} & \multicolumn{2}{|c|}{ Before } & \multicolumn{2}{|l|}{ After } & \multirow{2}{*}{$\begin{array}{l}\text { Calculated } \\
\text { (t) value }\end{array}$} & \multirow{2}{*}{$\begin{array}{l}T \text { tabular } \\
\text { value }\end{array}$} & \multirow[t]{2}{*}{ Significance } \\
\hline & & $-S$ & a & $-s$ & a & & & \\
\hline $150 \mathrm{M}$ & & 67.62 & 0.03 & 65.1 & 0.04 & 3.5 & & Moral \\
\hline $350 \mathrm{M}$ & Degree & 67.13 & 1.02 & 64.55 & 1.01 & 3.71 & 2.57 & Moral \\
\hline $550 \mathrm{M}$ & & 65.1 & 0.05 & 63.87 & 0.07 & 2.67 & & Moral \\
\hline $750 \mathrm{M}$ & & 64.27 & 0.06 & 62.92 & 0.01 & 2.65 & & Moral \\
\hline
\end{tabular}

Table (1) shows the rising angle variable for (150) $\mathrm{m}$ that the arithmetic mean for the pre-test was (67.62) and a standard deviation (0.03), while the arithmetic mean for the post-test was (65.10) and a standard deviation (0.04). And the calculated ( $T$ ) value for the differences between the pre and post- test was (3.50), which is greater than the tabular value of $(2.57)$ at a freedom degree 5 , and below the significance level (0.05). This indicates significant differences between the pre-test and the post-test and in favour of the posttest.

While the distance for (350) $\mathrm{m}$ that the arithmetic mean for the pre-test was (67.13), and a standard deviation (1.02), while the arithmetic mean for the post-test was (64.55) and a standard deviation (1.01). And the calculated $(T)$ value for the differences between the pre and post- test was (3.71), which is greater than the tabular value of (2.57) at a freedom degree 5 , and below the significance level (0.05). This indicates significant differences between the pre-test and the post-test and in favour of the post-test.

While the distance for (550) $\mathrm{m}$ that the arithmetic mean for the pre-test was (65.10), and a standard deviation (0.05), while the arithmetic mean for the post-test was (63.87) and a standard deviation (0.07). And the calculated $(T)$ value for the differences between the pre and post- test was $(2,67)$, which is greater than the tabular value of (2.57) at a freedom degree 5 and below the significance level (0.05). This indicates significant differences between the pre-test and the post-test and in favour of the post-test.

While the distance for (750) $\mathrm{m}$ that the arithmetic mean for the pre-test was (64.27), and a standard deviation (0.06), while the arithmetic mean for the post-test was (62.92) and a standard deviation (0.01). And the calculated $(T)$ value for the differences between the pre and post-test was $(2,65)$, which is greater than the tabular value of (2.57) at a freedom degree 5 and below the significance level (0.05). This indicates significant differences between the pre-test and the post-test and in favour of the post-test.

In Table 1 we noticed that all tests distances values were moral, and in favour of the post-tests for the rising angle variable, which means that there is progress in the rising phase. 
This shows that the proposed exercises have contributed primarily to improve ratios of this variable.

As this variable determines the elevation to identify the maximum height possible, and this can be through high-weighted arms forward at the rising moment.

Resulting in the movement of the body parts to change the position of the body weight which is supposed to exist above the pelvic level in case of the normal stand, so the movement of the arms will help to transfer of the centre of the body weight to the top, which contributes to its rise before the departure and therefore it is important to note that the weight of the arms correctly during the rising stage, and this is in line with what (Qasim Hassan Hussein and Iman Shaker) had mentioned.

Therefore, when observing the values of the arithmetic circles the lack of these values appear, which means that the rising angle during the race stage is small, and logically the smallness in this angle drives the resultant of the cruising speed in the horizontal direction to a greater extent, which means the frequency of the step increases at the expense of its length.

Also, the values of vertical occupancy performed by the player at the start of each step of the race are reduced, which means that the kinetic work during this performance is positive, because the reduction of vertical pressure is economical in motor performance, and that's because in the final outcome can benefit from the energy reserve available at every step of the performance, which results in an increase in the speed rate and this is consistent with what Talha Hossam El Din had said.

View, analyse, and discuss the results of the search sample tests for Landing Angle variable.

Table 2. Arithmetic mean, standard deviation, and Calculated (T) tabular value for the post, and pre-tests for landing angle variables

\begin{tabular}{|c|c|c|c|c|c|c|c|c|}
\hline \multirow{2}{*}{ Variable } & \multirow{2}{*}{$\begin{array}{l}\text { Measure } \\
\text { Unit }\end{array}$} & \multicolumn{2}{|c|}{ Before } & \multicolumn{2}{|l|}{ After } & \multirow{2}{*}{$\begin{array}{l}\text { Calculated } \\
\text { (t) value }\end{array}$} & \multirow{2}{*}{$\begin{array}{l}T \text { tabular } \\
\text { value }\end{array}$} & \multirow{2}{*}{ Significance } \\
\hline & & $-s$ & a & $-s$ & a & & & \\
\hline $150 \mathrm{M}$ & & 71.64 & 1.06 & 70.09 & 1.04 & 2.9 & & Moral \\
\hline $350 \mathrm{M}$ & Degree & 72.2 & 1.02 & 70.45 & 1.03 & 3.27 & 2.57 & Moral \\
\hline $550 \mathrm{M}$ & & 73.13 & 1.06 & 70.71 & 0.06 & 3.35 & & Moral \\
\hline $750 \mathrm{M}$ & & 73.31 & 1.08 & 71.02 & 0.07 & 3.22 & & Moral \\
\hline
\end{tabular}

Table (2) shows the change in the landing angle for $(150) \mathrm{m}$. That the arithmetic mean for the pre-test was (71.64) and a standard deviation (1.06), while the arithmetic mean for the post-test was (70.09) and a standard deviation (1.04). And the calculated (T) value for the differences between the pre and post- test was $(2,90)$, which is greater than the table value of $(2.57)$ at a freedom degree 5 and below the significance level $(0.05)$. This indicates significant differences between the pre-test and the post-test and in favour of the posttest.

While the distance for $(350 \mathrm{~m}$ ) that the arithmetic mean for the pre-test was $(72.20)$, and a standard deviation (1.02), while the arithmetic mean for the post-test was (70.45) and a standard deviation (1.03). And the calculated $(T)$ value for the differences between the pre and post- test was $(3,27)$, which is greater than the table value of (2.57) at a freedom degree 5and below the significance level $(0.05)$. This indicates significant differences between the pre-test and the post-test and in favour of the post-test. 
While the distance for $(550 \mathrm{~m})$ that the arithmetic mean for the pre-test was $(65.10)$, and a standard deviation (0.05), while the arithmetic mean for the post-test was (63.87) and a standard deviation (0.07). And the calculated $(T)$ value for the differences between the pre and post- test was $(2,67)$, which is greater than the table value of (2.57) at a freedom degree 5 and below the significance level $(0.05)$. This indicates significant differences between the pre-test and the post-test and in favour of the post-test.

While the distance for $(750 \mathrm{~m})$ that the arithmetic mean for the pre-test was (73.31), and a standard deviation (1.08), while the arithmetic mean for the post-test was (71.02) and a standard deviation (1.07). And the calculated $(T)$ value for the differences between the pre and post-test was $(3,22)$, which is greater than the table value of (2.57) At a freedom degree 5 and below the significance level (0.05). This indicates significant differences between the pre-test and the post-test and in favour of the post-test.

In Table (2) we noticed that all values of test distances were moral and in favour of the post-tests of the landing angle variable, which means that there is a decrease in the landing phase.

Which means that the proposed exercises have contributed primarily to improve ratios of this variable.

Researcher attribute this to the fact that the $800 \mathrm{~m}$ race is one of the races that need the step frequency at the expense of their length, which means that a decrease in the arc of aviation for the runner's gravity centre, which reflects that positively to decrease in the landing angle values, and increase the amount of horizontal velocity at the expense of vertical velocity.

This situation is positive in terms of providing an adequate kinetic extension, which contributes to reducing the disability in the introductory section and reducing the collision force between the runner's foot and the ground.

And this occurs by bending the joint (foot-knee-hip) of the support leg, which contributes to keeping the trajectory of the runner's body smoothly to the transitional stage between the front and back support before proceeding to the second step which is the moment of landing on the ground.

View, analyse, and discuss the results of the search sample tests for the speed rate variable.

Table 3. Arithmetic means, standard deviation, and Calculated and tabular values of the post, and pre-tests for speed rate variable

\begin{tabular}{|c|c|c|c|c|c|c|c|c|}
\hline \multirow{2}{*}{ Variable } & \multirow{2}{*}{$\begin{array}{l}\text { Measure } \\
\text { Unit }\end{array}$} & \multicolumn{2}{|c|}{ Before } & \multicolumn{2}{|l|}{ After } & \multirow{2}{*}{$\begin{array}{l}\text { Calculated } \\
\text { (t) value }\end{array}$} & \multirow{2}{*}{$\begin{array}{l}\mathrm{T} \text { tabular } \\
\text { value }\end{array}$} & \multirow{2}{*}{ Significance } \\
\hline & & $-s$ & a & $-s$ & a & & & \\
\hline $150 \mathrm{M}$ & & 4.29 & 0.03 & 4.7 & 0.02 & 2.7 & & Moral \\
\hline $350 \mathrm{M}$ & $\mathrm{M} / \mathrm{S}$ & 4.41 & 0.06 & 5.01 & 0.02 & 2.81 & 2.57 & Moral \\
\hline $550 \mathrm{M}$ & & 4.38 & 0.02 & 4.9 & 0.03 & 2.83 & & Moral \\
\hline $750 \mathrm{M}$ & & 4.1 & 0.04 & 4.39 & 0.04 & 2.64 & & Moral \\
\hline
\end{tabular}

Table (3) shows the change in the speed rate for (150) $\mathrm{m}$ that the arithmetic mean for the pre-test was (4.29) and a standard deviation (0.03), while the arithmetic mean for the post-test was (4.70) and a standard deviation (0.02). And the calculated $(T)$ value for the differences between the pre and post- test was $(2,70)$, which is greater than the table value of (2.57) at a freedom degree 5and below the significance level (0.05). This indicates significant differences between the pre-test and the post-test and in favour of the post-test. 
While the distance for (350 m) that the arithmetic mean for the pre-test was (4.41), and a standard deviation (0.06), while the arithmetic mean for the post-test was (5.01) and a standard deviation (0.02). And the calculated $(T)$ value for the differences between the pre and post- test was $(2,81)$, which is greater than the table value of (2.57) At a freedom degree 5and below the significance level (0.05).

This indicates significant differences between the pre-test and the post-test and in favour of the post-test While the distance for $(550 \mathrm{~m})$ that the arithmetic mean for the pre-test was (4.38), and a standard deviation (0.02), while the arithmetic mean for the post-test was (4.90) and a standard deviation (0.03). And the calculated $(T)$ value for the differences between the pre and post- test was $(2,83)$, which is greater than the table value of (2.57) at a freedom degree 5 and below the significance level (0.05). This indicates significant differences between the pre-test and the post-test and in favour of the post-test.

While the distance for $(750 \mathrm{~m})$ that the arithmetic mean for the pre-test was (4.10), and a standard deviation (0.04), while the arithmetic mean for the post-test was (4.39) and a standard deviation (0.04). And the calculated $(T)$ value for the differences between the pre and post-test was $(2,64)$, which is greater than the table value of (2.57) at a freedom degree 5and below the significance level (0.05). This indicates significant differences between the pre-test and the post-test and in favour of the post-test.

From the above table 3, the researcher believes that there is a moral difference in favour of the post-test which indicates an increase in the player's speed rate during the $800 \mathrm{~m}$ running race. And the researcher attributed the reason for this development to the content of the proposed training curriculum of exercises that emphasize the development of maximum speed, and afford the speed and the remaining other qualities related to the performance level as well as the correct kinetic construction for the jogging step movement, which contributes to reducing the effort and directing the force in the right direction For the purpose of practicing sports activity, all these factors led to increase the runner's speed during the test, which reflected positively on the performance level.

Researcher agree with Qassim Hassan Husain "that the good qualities of the runner are to have the ability to expand the step length and repeat them simultaneously.

Therefore, Medium-distance runner must be characterized by a regular speed and energy economy, because the speed change depends on the change in the power values based on Newton's first law, which confirms the body's need for additional energy in case of speed change, and there are three elements for the success of the medium-distance runner, which are: Speed, kinetic sufficiency and oxygen and non-oxygen endurance.

The kinetic efficiency includes interrelationship between step length and step frequency, as increasing one or both increases velocity. (Vittory), 1995 notes that (the optimal balance between the step length and frequency contributes effectively to improving the speed rate).

View, analyse, and discuss the results OF the search sample tests for the step length variable.

Table (4) shows the change in the step length for (150) $\mathrm{m}$ that the arithmetic mean for the pre-test was (1.34) and a standard deviation (0.06), while the arithmetic mean for the post-test was (1.64) and a standard deviation (0.03). And the calculated $(T)$ value for the differences between the pre and post- test was $(2,60)$, which is greater than the table value of (2.57) at a freedom degree 5and below the significance level (0.05). This indicates significant differences between the pre-test and the post-test and in favour of the post-test. 
Table 4. Arithmetic mean, standard deviation, and Calculated $(\mathrm{T})$ and tabular values for the post and pretests for step length variable

\begin{tabular}{|c|c|c|c|c|c|c|c|c|}
\hline \multirow{2}{*}{ Variable } & \multirow{2}{*}{$\begin{array}{l}\text { Measure } \\
\text { Unit }\end{array}$} & \multicolumn{2}{|c|}{ Before } & \multicolumn{2}{|c|}{ After } & \multirow{2}{*}{$\begin{array}{l}\text { Calculated } \\
\text { (t) value }\end{array}$} & \multirow{2}{*}{$\begin{array}{l}\mathrm{T} \text { tabular } \\
\text { value }\end{array}$} & \multirow{2}{*}{ Significance } \\
\hline & & $-s$ & a & $-s$ & a & & & \\
\hline $150 \mathrm{M}$ & \multirow{3}{*}{$\begin{array}{l}\text { Measure } \\
\text { Unit }\end{array}$} & 2.6 & 0.03 & 1.64 & 0.06 & 1.34 & & Moral \\
\hline $350 \mathrm{M}$ & & 2.7 & 0.03 & 1.66 & 0.02 & 1.36 & 2.57 & Moral \\
\hline $\begin{array}{l}550 \mathrm{M} \\
750 \mathrm{M}\end{array}$ & & $\begin{array}{l}2.63 \\
3.42\end{array}$ & $\begin{array}{l}0.04 \\
0.02\end{array}$ & $\begin{array}{l}1.61 \\
1.7\end{array}$ & $\begin{array}{l}0.03 \\
0.05\end{array}$ & $\begin{array}{l}1.33 \\
1.39\end{array}$ & & $\begin{array}{l}\text { Moral } \\
\text { Moral }\end{array}$ \\
\hline
\end{tabular}

While the distance for $(350 \mathrm{~m}$ ) that the arithmetic mean for the pre-test was (1.36), and a standard deviation $(0.02)$, while the arithmetic mean for the post-test was (1.66) and a standard deviation $(0.03)$. And the calculated $(\mathrm{T})$ value for the differences between the pre and post- test was $(2,70)$, which is greater than the table value of (2.57) At a freedom degree 5 and below the significance level $(0.05)$. This indicates significant differences between the pre-test and the post-test and in favour of the post-test.

While the distance for $(550 \mathrm{~m})$ that the arithmetic mean for the pre-test was (1.33), and a standard deviation (0.03), while the arithmetic mean for the post-test was (1.61) and a standard deviation (0.04). And the calculated $(T)$ value for the differences between the pre and post- test was $(2,63)$, which is greater than the table value of (2.57) at a freedom degree 5 and below the significance level $(0.05)$. This indicates significant differences between the pre-test and the post-test and in favour of the post-test.

While the distance for $(750 \mathrm{~m})$ that the arithmetic mean for the pre-test was (1.39), and a standard deviation $(0.05)$, while the arithmetic mean for the post-test was (1.70) and a standard deviation (0.02). And the calculated $(T)$ value for the differences between the pre and post-test was $(3,42)$, which is greater than the table value of (2.57) at a freedom degree 5 and below the significance level $(0.05)$. This indicates significant differences between the pre-test and the post-test and in favour of the post-test.

Researcher reviewed the result shown in table 4, and they noticed that there is a moral difference in favour of the post-test. They believed that this evolution is moral in the step length through the race distance, and the reason for this evolution is due to the proposed training curriculum and its content of exercises to emphasize the development of power and speed qualities and its compounds, which has worked to increase the positive propulsion at the end for the rear fulcrum by the full stretch for the legs joints driven and compatible with the weighted movements for the free legs and arms, which in turn led to an increase in flight time

The researcher agrees with Qasim Hassan Hussein, "When the speed increases, there is an increase either in the length or frequency of the step.

Deyaa Al Talib also mentioned that "the step length continues to increase until the athlete reaches his maximum speed.

View, analyse and discuss the results of the research sample for achievement. 
Table 5. Arithmetic means, standard deviation, and Calculated (T) tabular value of the post, and pre-tests for achievement

\begin{tabular}{|c|c|c|c|c|c|c|c|c|}
\hline \multirow{2}{*}{ Variable } & \multirow{2}{*}{$\begin{array}{l}\text { Measure } \\
\text { Unit } \\
\end{array}$} & \multicolumn{2}{|c|}{ Before } & \multicolumn{2}{|l|}{ After } & \multirow{2}{*}{$\begin{array}{l}\text { Calculated } \\
\text { (t) value }\end{array}$} & \multirow{2}{*}{$\begin{array}{l}T \text { tabular } \\
\text { value }\end{array}$} & \multirow{2}{*}{ Significance } \\
\hline & & $-S$ & $a$ & $-s$ & a & & & \\
\hline $\begin{array}{lr}800 & \mathrm{M} \\
\text { achievement }\end{array}$ & Second & 2.06 & 1.03 & 2.01 & 1.01 & 3.98 & 2.57 & Moral \\
\hline
\end{tabular}

Table (5) shows the achievement that the arithmetic mean for the pre-test was (2.06) and a standard deviation (1.03), while the arithmetic mean for the post-test was (2.01) and a standard deviation (1.01). And the calculated $(T)$ value for the differences between the pre and post- test was $(2,60)$, which is greater than the table value of (2.57) At a freedom degree 5 and below the significance level $(0.05)$. This indicates significant differences between the pre-test and the post-test and in favour of the post-test.

From the above through table 5 , the researcher sees that there is a moral difference in favour of the posttest; and this development was due to the improvement in the fitness level (general endurance - bearing speed, carrying power and maximum speed) for the research sample personnel, as a result of the proposed training method.

The training has been prepared in a way that helps to develop the completion of the 800 meters running activity and the power and speed that it needs, and this is what Risan Khreibut had said.

"Regular and programmed training and the use of metered-intensity types in training using optimum comfort between repetition leads to the development of achievement". Therefore, we see that the distribution of the effort was according to the speed rate required for each athlete so that the focus when training this event is on the exercises with less intensity than the maximum that is compared to the type for the competition, so that there is an adaptation in the Functional systems of the athlete's body and their capacity, to perform the vigorously very effectively with distances, duplicates distribution, and breaks between duplicates depending on the return of the pulse to its normal state.

\section{CONCLUSIONS}

The proposed exercises contributed very clearly and effectively in developing the speed rate. And it had an obvious effect on developing the step length.

The researcher advises the Iraqi trainers to rely on effective modern methods, and incorporate them into their training programs and the need to emphasize on developing the kinematic variables during.

\section{Recommendations}

-The researcher recommend that Iraqi trainers rely on modern and effective training methods and incorporate them into training programs.

-The need to emphasize on developing of kinematics variables during the 800 meters running training.

-Conduct studies similar to this study. 


\section{REFERENCES}

El Din, T. H. (1993). Mathematical and functional foundations for sports training. Cairo, Egypt: Dar AlFikr Al-Arabi.

Hussein, Q. H. (1976). The basic rules for teaching the arena and field games in jogging and jumping activities. Baghdad, Baghdad: Freedom House.

Hussein, Q. \& Shaker E. (2000). Mechanical, analytical and technical foundations in the Arena and Race track activities, Amman, Jordan, Dar Al-Fikr for printing, publishing and distribution.

Khreibut, R. (1989). Applications in Physiology and Sports Training. Baghdad, Baghdad: Noon for Sports Preparation.

Mahjoub, W. (2001). Principles of Scientific Research and its Methods. Amman, Jordon: Dar Al Fikr for Printing, Publishing and Distribution.

Talib, D. M. (1988). The entrance to the decimal games for men and the seventh for women. Mosul, Nineveh: Directorate of Dar al-Kutub Printing and Publishing. 